\title{
Study Day of Pharmacokinetic Concentration
}

National Cancer Institute

\section{Source}

National Cancer Institute. Study Day of Pharmacokinetic Concentration. NCI Thesaurus.

Code C87952.

The day that an pharmacokinetic concentration assessment is performed. 